J. Dairy Sci. 95:2872-2881

http://dx.doi.org/10.3168/jds.2011-5146

(C) American Dairy Science Association ${ }^{\circledR}, 2012$.

\title{
Rapid determination of sodium in milk and milk products by capillary zone electrophoresis
}

\author{
F. Masotti, ${ }^{1}$ D. Erba, I. De Noni, and L. Pellegrino \\ Dipartimento di Scienze e Tecnologie Alimentari e Microbiologiche, Università degli Studi di Milano, 20133 Milano, Italy
}

\begin{abstract}
A capillary zone electrophoresis method for the determination of $\mathrm{Na}$ in milk and milk products was developed and compared with an International Organization for Standardization/International Dairy Federation standard method that is based on flame atomic absorption spectrometry. The adoption of a background electrolyte consisting of $10 \mathrm{~m} M$ imidazole adjusted to $\mathrm{pH} 3.75$ by the addition of oxalic acid allowed baseline separation of $\mathrm{Na}$ from other milk cations and from $\mathrm{Li}$ ion, which was adopted as an internal standard. Method validation was performed and the results for linearity, precision, limit of detection, limit of quantification, and recovery are presented. The procedure was tested on commercial milk samples differing in fat content (whole, semiskimmed, and skimmed) and processing conditions (pasteurization, UHT sterilization, and microfiltration). The reliability of the method was confirmed for different varieties of cheese and other milk products. The method enables the routine measurement of $\mathrm{Na}$ content by a rapid and accurate capillary zone electrophoresis procedure.
\end{abstract}

Key words: sodium, milk, milk product, capillary zone electrophoresis

\section{INTRODUCTION}

The consumption of large amounts of sodium has been cited as a primary cause of hypertension and the development of cardiovascular diseases (Kaplan, 2000). Accordingly, in 2010, the World Health Organization and the UK Food Standards Agency agreed on interventions for consumer education and reformulation of industrially produced foods to enable consumers to make appropriate choices in reducing the total Na content of their diets (WHO, 2010).

Salt is the main source of $\mathrm{Na}$ in the human diet and is traditionally used in a variety of food products to modify not only the final sensory characteristics but

Received November 14, 2011.

Accepted February 4, 2012.

${ }^{1}$ Corresponding author: fabio.masotti@unimi.it also the shelf life, because of its efficacy against pathogenic and spoilage microorganisms. Several $\mathrm{Na}$ salts (e.g., lactate, citrate, bicarbonate, and glutamate) with numerous important processing functions are used in food manufacturing; these salts contribute to the overall consumption of Na. Therefore, specific research is required on the technological implications of $\mathrm{Na}$ reduction or replacement in prepared foods because data appear to be lacking in this area. Fast and easily applied analytical methods for $\mathrm{Na}$ determination would greatly assist the food industry in addressing this issue.

Sodium is present in cow milk, mainly as a free ion, at concentrations ranging from 47 to $77 \mathrm{mg} / 100$ g (Jenness et al., 1999), with an average level of 51 mg (Gaucheron, 2011). Guinee and Fox (2004) have reported levels of salt in cheese ranging from $0.7 \%$ in Emmentaler to $6 \%$ in Domiati. More recently, Cruz et al. (2011) reported the content of $\mathrm{Na}$ in cheese to range between approximately $60 \mathrm{mg} / 100 \mathrm{~g}$ in Quark cheese and $1,770 \mathrm{mg} / 100 \mathrm{~g}$ in Feta cheese.

The amount of Na present is usually greater in processed cheeses than in natural cheeses because of the addition of emulsifying salts (3\% or more) or preserving agents such as Na propionate (Guinee and Fox, 2004). Therefore, widely differing Na contents have to be measured in milk products.

The determination of $\mathrm{Na}$ in milk products can be performed by several instrumental techniques (Soyeurt et al., 2009; Ehling et al., 2010), including indirect photometric chromatography, ion chromatography, flame atomic absorption spectrometry (FAAS), inductively coupled plasma optical emission spectrometry, inductively coupled plasma atomic emission spectrometry, and mid-infrared spectrometry. Currently, the reference analytical method for the determination of $\mathrm{Na}$ in milk and dairy products, validated by the International Organization for Standardization and the International Dairy Federation (ISO/IDF), is based on FAAS (ISO/ IDF, 2007), although this technique requires a laborintensive pretreatment of the sample. Interlaboratory trials on samples of various milk and dairy products, which were submitted to mineralization and then analyzed in parallel using FAAS and inductively coupled plasma optical emission spectrometry, indicated better 
precision for the latter method (ISO/IDF, 2007). However, for practical use, the 2 techniques could be considered equivalent with respect to the results. Poitevin et al. (2009) reported an improved version of AOAC Official Method 984.27 (AOAC, 2007) for the determination of $\mathrm{Na}$ and other elements in food products by inductively coupled plasma atomic emission spectrometry. More recently, the ISO/IDF (2010) published a working draft on Na determination in milk and dairy products by this last technique to demonstrate equivalence of its alternative.

Reviews on metal ion analyses in different food matrices are available (Macka and Haddad, 1997; Sádecká and Polonský, 1999). The separation of metal ions by capillary zone electrophoresis (CZE) has become widespread since the early 1990s, when robust and affordable instrumentation was made available. This technique has been optimized and currently represents a powerful tool for inorganic ion analyses. It is also a valuable alternative to ion chromatography (Valsecchi and Polesello, 1999). Capillary zone electrophoresis has high resolution power and efficiency, allows short analysis times, and requires minimal preparation of samples, even in complex matrices (Mato et al., 2005). Pretswell et al. (1995) compared CZE and FAAS methods for the determination of the $\mathrm{Na}$ content in milk powder. Although only one sample was analyzed, the results indicated no systematic differences between the 2 procedures. Suárez-Luque et al. (2007) proposed a rapid CZE method for the determination of the major cations in milk. The separation was accomplished in 4 min with $10 \mathrm{~m} M$ imidazole as the background electrolyte (BGE) and acetic acid as the complexing agent. However, the resolution between $\mathrm{Na}$ and $\mathrm{Mg}$ peaks appears to be critical, and detection at $185 \mathrm{~nm}$ requires a specific wavelength filter.

In this study, we describe a new CZE method, in which a BGE containing imidazole is adopted as the indirect UV co-ion and oxalic acid is adopted as the complexing agent, for the separation and quantification of Na in milk and milk products. The reference FAAS method was used for comparison purposes.

\section{MATERIALS AND METHODS}

\section{Chemicals and Reagents}

Chemicals of analytical grade (Sigma-Aldrich, St. Louis, MO) and purified water (Milli-Q Plus, Millipore, Bedford, MA) were used throughout the experiments. Aqueous solutions of cations ( $\mathrm{Na}, \mathrm{K}, \mathrm{Ca}, \mathrm{Mg}$, and $\mathrm{Li}$ ) were prepared from chloride salts. Nitric acid (Suprapur grade) for the FAAS analysis was purchased from Merck (Darmstadt, Germany).

\section{Milk and Milk Product Samples}

Commercial samples of unprocessed $(\mathrm{n}=2)$, pasteurized (whole, semiskimmed, and skimmed; $\mathrm{n}=4$ ), microfiltered pasteurized (semiskimmed, $\mathrm{n}=2$ ), and UHT-sterilized (semiskimmed, $\mathrm{n}=2$ ) cow milk were analyzed. In addition, other milk products $(\mathrm{n}=8)$ purchased at a local store were submitted to analysis.

\section{Equipment}

Electrophoretic separations were performed on a capillary electrophoresis apparatus (P/ACE MDQ, Beckman Coulter, Fullerton, CA) equipped with a diode array detector. A bare fused-silica capillary (Agilent, Milan, Italy) of $50 \mu \mathrm{m}$ i.d. and $60 \mathrm{~cm}$ total length (50 $\mathrm{cm}$ to the detector window) was adopted. Data acquisition and processing were performed with the 32 Karat software package (Beckman Coulter). The new capillary column was conditioned by flushing with purified water (10 $\mathrm{min}), 1 \mathrm{M}$ sodium hydroxide (10 $\mathrm{min})$, purified water $(30 \mathrm{~min})$, and $\mathrm{BGE}(60 \mathrm{~min})$ in sequence with a pressure of $138 \mathrm{kPa}$. Prior to each run, the capillary was flushed with the BGE for 2 min. After daily analyses, the capillary was washed by flushing with $10 \mathrm{mM}$ sodium hydroxide (5 min) and purified water (30 min). Samples were introduced into the capillary column by hydrodynamic injection at $7 \mathrm{kPa}$ for $12.5 \mathrm{~s}$. Analyses were performed at $25^{\circ} \mathrm{C}$ using a separation voltage of 25 $\mathrm{kV}$ and with UV detection at $206 \mathrm{~nm}$.

Analyses by FAAS were performed on an AAnalyst 800 spectrometer (PerkinElmer, Covina, CA). Oxidant air and acetylene flames were used, and readings were taken at $589.6 \mathrm{~nm}$. No background correction was performed.

\section{CZE Analysis}

Preparation of Test Samples. For fluid products, sample portions of $2 \mathrm{~g}$ to the nearest $1 \mathrm{mg}$ were weighed and added to $2 \mathrm{~mL}$ of $\mathrm{Li}$ aqueous solution $(1 \mathrm{~g} / \mathrm{L})$ and $75 \mathrm{~mL}$ of purified water. The mixture was acidified to $\mathrm{pH} 4.60 \pm 0.05$ by dropwise addition of $0.1 \mathrm{M}$ oxalic acid, diluted to $100 \mathrm{~mL}$ in a volumetric flask and filtered through a $0.22-\mu \mathrm{m}$ membrane filter (Millipore) before analysis.

For solid products, sample portions of $2 \mathrm{~g}$ to the nearest $1 \mathrm{mg}$ were added to approximately $50 \mathrm{~mL}$ of purified water, homogenized using an Ultraturrax (IKA Labortechnik, Staufen, Germany) for 2 min, and quantitatively transferred to a $100-\mathrm{mL}$ volumetric flask. Twenty milliliters of this dispersion was added to $2 \mathrm{~mL}$ of $\mathrm{Li}$ aqueous solution and $50 \mathrm{~mL}$ of purified water and treated as described previously for fluid products. 
For the skim milk powder (SMP) sample, portions of $200 \mathrm{mg}$ to the nearest $1 \mathrm{mg}$ were added to $2 \mathrm{~mL}$ of $\mathrm{Li}$ aqueous solution and $75 \mathrm{~mL}$ of purified water, and the mixture was treated in the same manner as fluid products. In addition, SMP was reconstituted with water $(4.5 \mathrm{~g}$ to the nearest $1 \mathrm{mg}$ to a final volume of $50 \mathrm{~mL}$ ) under stirring for about $30 \mathrm{~min}$. Two milliliters of reconstituted SMP was thereafter treated as a fluid product.

Standard Solutions. Sodium quantification was performed by a multi-point calibration with standard solutions $(\mathrm{n}=7)$ in the range from 0 to $2.95 \mathrm{mg} / 100$ $\mathrm{mL}$ that were prepared by diluting a $\mathrm{NaCl}$ stock solution $(150 \mathrm{mg} / \mathrm{L})$ with purified water. Such solutions were prepared as described previously for fluid test samples.

$\boldsymbol{B} \boldsymbol{G} \boldsymbol{E}$. The BGE consisting of $10 \mathrm{~m} M$ imidazole adjusted to $\mathrm{pH} 3.75 \pm 0.02$ with $0.1 \mathrm{M}$ oxalic acid (flow modifier) was prepared daily. Other tested experimental BGE and flow modifiers are described throughout the text.

\section{Sample Preparation and Analysis by FAAS}

Milk samples and milk products were weighed $(0.1-0.5 \mathrm{~g})$ to the nearest $0.1 \mathrm{mg}$ in a polytetrafluoroethylene vessel and added to nitric acid (65\% wt/wt, $7 \mathrm{~mL}$ ); a blank sample was included in each digestion batch. Vessels were placed in a microwave wet digestion system (Ethos TC, Milestone, Shelton, CT), and the decomposition program was applied according to the ISO/IDF (2007) method. Cooled digest solutions were transferred quantitatively into a $50-\mathrm{mL}$ volumetric flask with purified water.

The sodium concentration $(\mathrm{mg} / 100 \mathrm{~g})$ in digest solutions was calculated through an external calibration curve by using the following equation:

$$
\mathrm{Na}=100 \times \mathrm{F} \times \mathrm{V} \times\left(\mathrm{C}_{\mathrm{s}}-\mathrm{C}_{\mathrm{b}}\right) / \mathrm{w},
$$

where $\mathrm{V}$ is the volume $(\mathrm{L})$ of the solution after being made up; $\mathrm{F}$ is the dilution factor; $\mathrm{C}_{\mathrm{s}}$ and $\mathrm{C}_{\mathrm{b}}$ are the concentrations $(\mathrm{mg} / \mathrm{L})$ of the test and the blank solutions, respectively, and $\mathrm{w}$ is the weight $(\mathrm{g})$ of the test portion.

\section{CZE Method Validation}

The normalized peak area ratio; that is, the peak area/migration time $\left(\mathbf{t}_{\mathrm{m}}\right)$ of $\mathrm{Na}$ divided by the peak area $/ \mathrm{t}_{\mathrm{m}}$ of $\mathrm{Li}$, was the response used to validate the method. The sodium concentration $(\mathrm{mg} / 100 \mathrm{~g})$ in the test portion sample was calculated by using the following equation:

$$
\mathrm{Na}=\mathrm{F} \times\left(\mathrm{C}_{\mathrm{s}}-\mathrm{C}_{\mathrm{b}}\right) / \mathrm{w},
$$

where $\mathrm{C}_{\mathrm{s}}$ and $\mathrm{C}_{\mathrm{b}}$ are the concentrations $(\mathrm{mg} / 100 \mathrm{~mL})$.

The limit of detection and the limit of quantification (LOQ), expressed as $\mathrm{mg} / 100 \mathrm{~mL}$, were estimated using the standard deviation (SD) approach by analyzing 6 replicates of a standard solution that contained 0.059 $\mathrm{mg}$ of $\mathrm{Na} / 100 \mathrm{~mL}$. In detail, the limit of detection was calculated as $3.3 \times \mathrm{SD}$, and the LOQ was calculated as $10 \times \mathrm{SD}$.

The experimental peak resolution $\left(\mathbf{R}_{\mathrm{s}}\right)$ was calculated by using the following equation:

$$
\mathrm{R}_{\mathrm{s}}=2 \times\left(\mathrm{t}_{\mathrm{m} 2}-\mathrm{t}_{\mathrm{m} 1}\right) /\left(\mathrm{w}_{1}+\mathrm{w}_{2}\right),
$$

where $t_{\mathrm{m} 2}$ and $t_{\mathrm{m} 1}$ are the $t_{\mathrm{m}}$ of 2 contiguous peaks and $\left(\mathrm{w}_{1}+\mathrm{w}_{2}\right)$ is the sum of the width of the 2 peaks calculated at the baseline between the tangents at half height.

The precision of the method was calculated on duplicate analyses of 4 milk samples performed on 5 different days. Intra- and interday parameters were referred to as repeatability (r) and within-laboratory reproducibility (R), respectively (Horwitz and Albert, 2006). Repeatability, R, relative standard deviation $\left(\mathbf{R S D}_{\mathbf{r}}\right.$ and $\left.\mathbf{R S D}_{\mathbf{R}}\right)$, relative repeatability $\left(\mathbf{r}_{\text {rel }}\right)$ and relative within-laboratory reproducibility $\left(\mathbf{R}_{\text {rel }}\right)$ values were calculated according to the IDF Standard (IDF, 1991). The reliability of these figures was assessed according to the Horwitz ratio HorRat $_{\mathbf{R}}$; Horwitz and Albert, 2006) using the equation:

$$
\text { HorRat }_{\mathrm{R}}=\mathrm{RSD}_{\mathrm{R}} / \mathrm{PRSD}_{\mathrm{R}} \text {, }
$$

where $\mathrm{RSD}_{\mathrm{R}}$ is the relative standard deviation of within-laboratory reproducibility of $\mathrm{Na}$, and $\mathrm{PRSD}_{\mathrm{R}}$ is the predicted relative standard deviation. The PRS$\mathrm{D}_{R}$ value is equal to $2 \mathrm{C}^{-0.15}$, where $\mathrm{C}$ represents the $\mathrm{Na}$ concentration expressed as a mass fraction. This equation considers only concentration, being independent of analyte and matrix type.

\section{Statistical Analysis}

Unless otherwise specified, 3 replicates were performed for each sample. Statistical significance between 2 data sets was determined using a 2-sided Student's $t$-test, and significance was set at $P<0.05$. 


\section{RESULTS AND DISCUSSION}

\section{Optimization of the CZE Analysis}

Milk cations are difficult to separate by CZE because their electrophoretic mobilities $\left(\mathbf{e}_{\mathbf{m}}\right)$ are similar. The selection of BGE is of utmost importance when developing a method that uses indirect UV detection (Izco et al., 2003). As reported by Pacáková et al. (1999), imidazole has been widely adopted as the BGE for cation separations. Pacáková et al. (1999) measured the following order of $\mathrm{e}_{\mathrm{m}}$ in $0.5 \mathrm{~m} M \mathrm{Ce}\left(\mathrm{SO}_{4}\right)_{2}$ electrolyte: $\mathrm{K}>\mathrm{Ca}>\mathrm{Na}>\mathrm{Mg}$. In any case, this pattern may be different due to the dependence of $\mathrm{e}_{\mathrm{m}}$ on both the composition and the $\mathrm{pH}$ value of the BGE. Imidazole is a heterocyclic amine that functions as the carrier electrolyte and background absorber for UV detection. The $e_{m}$ of imidazolium cation, which is close to the $e_{m}$ values of the analyzed cations, allows the minimization of electromigration dispersion and provides better peak resolution (Morin et al., 1995).

In this study, some BGE parameters (imidazole concentration, $\mathrm{pH}$, and type of complexing agent) that influence both the $\mathrm{e}_{\mathrm{m}}$ and the peak resolution of cations were investigated to find the optimal conditions for $\mathrm{Na}$ determination in milk and milk products.

Effect of Imidazole Concentration. The CZE patterns of cations in pasteurized milk (semiskimmed), obtained with a BGE at pH 3.75 (0.1 $M$ oxalic acid) that contained imidazole at different concentration levels $(1-20 \mathrm{~m} M)$ are shown in Figure 1. The Li ion was added as an internal standard to compensate for errors in sample handling and instrumental variability. Milk cations were identified by comparing the $t_{m}$ with those of standard solutions and by the spiking technique. When oxalic acid was used as a flow modifier, the $e_{m}$ of milk cations followed the order alkali $>$ alkaline earths. The increase of imidazole concentration caused a parallel increase in $t_{m}$, but at different rates for each cation. The sodium peak was well resolved $\left(\mathrm{R}_{\mathrm{s}} \geq 3.9\right.$, calculated by using Eq. [3]) from those of $\mathrm{K}$ and $\mathrm{Li}$ when the imidazole concentration was in the range from 5 to $20 \mathrm{mM}$ (Table 1), whereas the Li peak assumed a more symmetric shape at concentrations greater than $10 \mathrm{~m} M$. These results agree with those of François et al. (1995), who reported that imidazole was capable of creating a good resolution of milk cations, in the range from 5 to $15 \mathrm{mM}$ at $\mathrm{pH}$ 4.5. Other authors (Sze et al., 2007) reported that $10 \mathrm{~m} M$ imidazole allows a satisfactory sensitivity for alkali and alkaline-earth metals.

Attention was focused on $\mathrm{Na}$ and $\mathrm{Li}$ cations, and the $10 \mathrm{~m} M$ imidazole concentration was selected to provide both an acceptable $t_{m}$ and a suitable peak resolution.
Effect of $p H$ and Complexing Agent of the $\boldsymbol{B} \boldsymbol{G} \boldsymbol{E}$. The selected BGE (10 $\mathrm{m} M$ imidazole) was first acidified to different $\mathrm{pH}$ values $(3.0,3.3$, and 3.7$)$ by the addition of either $\mathrm{HCl}$ or $\mathrm{H}_{2} \mathrm{SO}_{4}$ (data not shown). When $\mathrm{HCl}$ was used, milk cations were separated in a shorter time span (4 min), but the resolution of $\mathrm{Na}$ and $\mathrm{Mg}$ peaks was low (maximum 0.9, at $\mathrm{pH} 3.0$ ), and the quantification was therefore unreliable. This behavior was minimally affected by the $\mathrm{pH}$ value of BGE, which was inversely related to the $t_{m}$ of the cations. The increase in the electrosmotic flow was responsible for the shorter run time at higher $\mathrm{pH}$ levels.

Acidification of $\mathrm{BGE}$ by $\mathrm{H}_{2} \mathrm{SO}_{4}$ in the $\mathrm{pH}$ range from 3.0 to 3.7 modified the separation performances in terms of the $e_{m}$, the resolution, and the asymmetry factor. The Na peak, in particular, was well resolved and showed $\mathrm{a}_{\mathrm{m}}$ of approximately $4 \mathrm{~min}$, irrespective of the $\mathrm{pH}$ value. However, the internal standard (Li) comigrated with $\mathrm{Mg}$ at all $\mathrm{pH}$ values. Sulfate anion likely behaves as a complexing agent and modifies the $t_{m}$ of divalent cations. Consequently, another mechanism of separation was investigated by the use of BGE that contained other complexing agents.

Lin et al. (1993) studied the effects of various acids as complexing agents in solutions that contained alkali and alkaline-earth cations. These authors verified that the $\mathrm{pH}$ of the carrier buffer influenced electrophoretic separation in a predictable way. The optimum $\mathrm{pH}$ for the separation of these ions is supposed to be approximately equal to the acid dissociation constant $\left(\mathbf{p} \boldsymbol{K}_{a}\right)$ of the adopted acid.

The separation of milk cations achieved using $10 \mathrm{~m} M$ imidazole in the presence of different organic acids as complexing agents is shown in Figure 2. The $\mathrm{pH}$ of the carrier buffer was set to approximately the $\mathrm{p} K_{a}$ value of each acid. Both lactic and hydroxyisobutyric acids allowed the shortest time interval between the first and the last migrating ions, whereas they were not effective toward $\mathrm{Na}$ and $\mathrm{Ca}$ resolution. However, in the presence of acetic acid and with the $\mathrm{pH}$ of BGE adjusted to 4.60, as proposed by Suárez-Luque et al. (2007), the selectivity improved. Under these conditions, alkali and alkaline-earth elements migrated slightly farther (Figure 2), and the $\mathrm{R}_{\mathrm{s}}$ of the $\mathrm{Ca}-\mathrm{Na}$ and $\mathrm{Na}-\mathrm{Mg}$ couples were 2.6 and 2.8 , respectively. The adoption of the diprotic oxalic acid allowed the best separation in terms of $R_{s}$ and $t_{m}$ of the 2 cations of interest.

Based on these observations, the BGE that consisted of $10 \mathrm{~m} M$ imidazole acidified to $\mathrm{pH} 3.75$ by oxalic acid was selected for further studies.

Effect of Temperature of the Capillary Column. Variations in the temperature of the capillary column may affect both the viscosity and conductiv- 
Table 1. Effect of imidazole concentration in the background electrolyte (acidified to $\mathrm{pH} 3.75$ by addition of oxalic acid) on separation of milk cations and Li (internal standard) by capillary zone electrophoresis in pasteurized milk

\begin{tabular}{|c|c|c|c|c|c|c|c|}
\hline \multirow[b]{2}{*}{ Item } & \multicolumn{7}{|c|}{ Imidazole concentration $(\mathrm{m} M)$} \\
\hline & 1 & 2 & 5 & 10 & 12 & 14 & 20 \\
\hline \multicolumn{8}{|c|}{ Migration time (min) } \\
\hline $\mathrm{Na}$ & 2.7 & 2.6 & 3.3 & 3.6 & 3.8 & 3.9 & 4.0 \\
\hline $\mathrm{Li}$ & 2.8 & 3.0 & 3.7 & 4.3 & 4.5 & 4.6 & 4.9 \\
\hline Current $(\mu \mathrm{A})$ & 1.6 & 2.3 & 4.3 & 7.6 & 8.5 & 10.1 & 15.2 \\
\hline \multicolumn{8}{|l|}{ Resolution } \\
\hline $\mathrm{K}-\mathrm{Na}$ & 2.2 & 3.4 & 5.0 & 7.4 & 10.1 & 9.7 & 12.3 \\
\hline $\mathrm{Na}-\mathrm{Li}$ & 1.1 & 2.3 & 3.9 & 7.4 & 8.9 & 8.7 & 11.8 \\
\hline $\mathrm{Li}-\mathrm{Ca}$ & 0.9 & 1.4 & 2.1 & 10.3 & 14.4 & 14.4 & 22.3 \\
\hline
\end{tabular}

ity of the electrolyte and the diffusion coefficient of the analytes. Consequently, the $\mathrm{e}_{\mathrm{m}}$ of the analytes may change as well (François et al., 1995). In this work, we investigated a range in column temperature from 20 to $45^{\circ} \mathrm{C}$. The increase in temperature promoted a parallel increase in conductivity such that current intensity

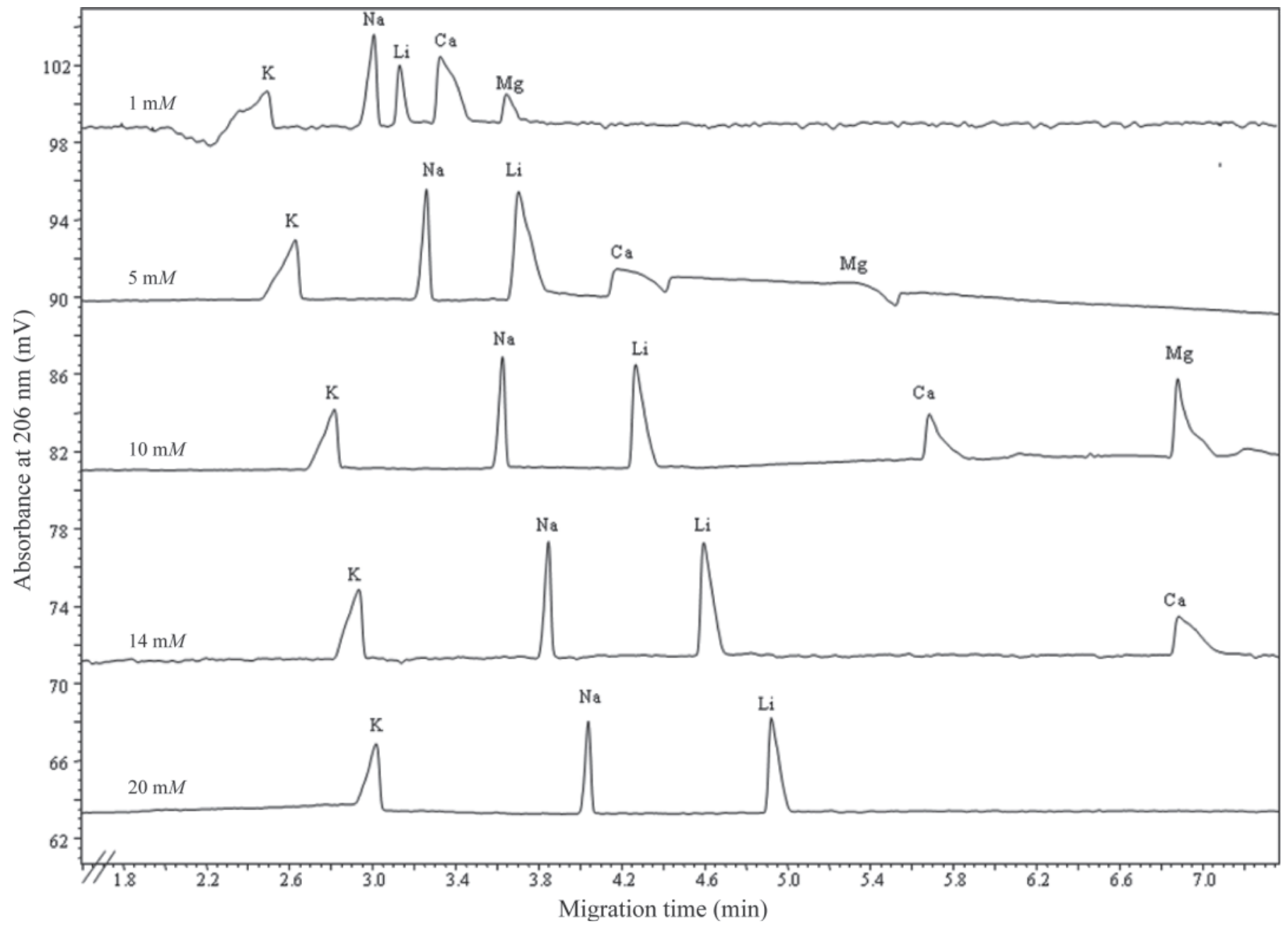

Figure 1. Capillary zone electrophoresis patterns of cations in pasteurized milk (plus Li as internal standard) obtained with a background electrolyte (acidified to $\mathrm{pH} 3.75$ with oxalic acid) that contained imidazole at different concentration levels. 


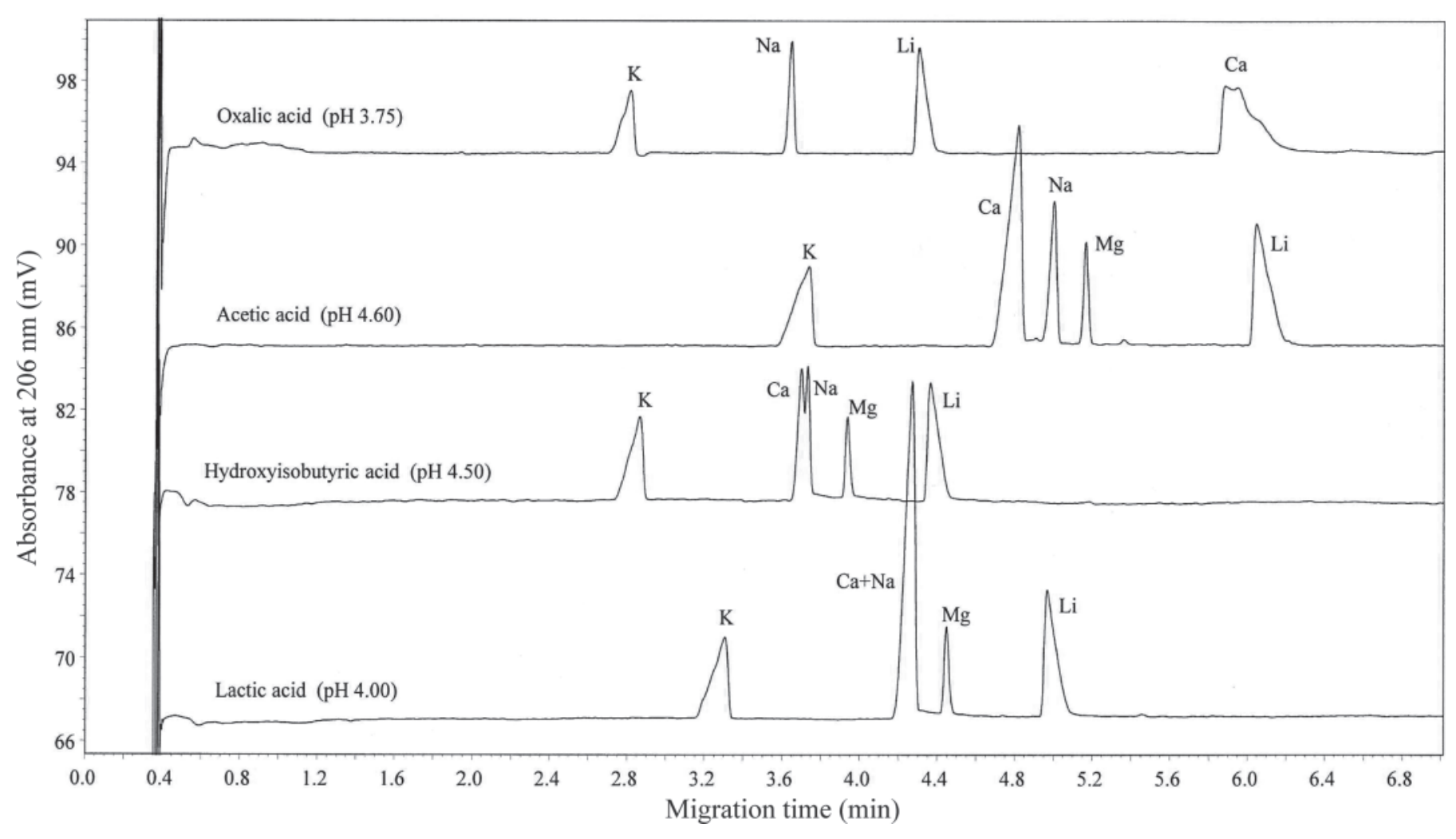

Figure 2. Capillary zone electrophoresis patterns of cations in pasteurized milk (plus Li as internal standard) obtained with a background electrolyte (10 $\mathrm{m} M$ imidazole) acidified with the addition of different complexing agents.

increased from 7.9 to $11.9 \mu \mathrm{A}$. Peak resolutions of K-Na and Na-Li couples increased from 5.8 and 5.7, respectively, at $45^{\circ} \mathrm{C}$, to 9.1 and 8.2 at $25^{\circ} \mathrm{C}$. As expected, the $t_{m}$ of ions was inversely related to the temperature, whereas the baseline noise was unaffected (results not shown). When the temperature of the capillary column was varied from 20 to $35^{\circ} \mathrm{C}$, the $\mathrm{Na}$ concentration of a pasteurized milk sample did not change (41 mg/100 g); thus, an operating temperature of $25^{\circ} \mathrm{C}$ was chosen.

Effect of Voltage. The progressive increase of the separation voltage from 10 to $25 \mathrm{kV}$ caused a reduction in the $t_{m}$ of cations (Table 2) and promoted the halving of the analysis time (from 11 to $5 \mathrm{~min}$ ). François et al. (1995), using an imidazole-based electrolyte containing the organic compound 18-crown-6 (IUPAC name: $1,4,7,10,13,16$-hexaoxacyclooctadecane), observed that an increase in voltage from 5 to $30 \mathrm{kV}$ produced an increase in peak resolution. In pasteurized milk, we observed a slight decrease in the resolution of the NaLi couple from 8.8 to 7.2. The increase of the applied voltage induced a parallel increase in current intensity from 5.0 to $7.8 \mu \mathrm{A}$, whereas no effect on baseline noise was observed. Because the normalized peak area ratio $\mathrm{Na}$ :Li did not change, the separation voltage was set at $25 \mathrm{kV}$ to allow a shorter analysis time.

\section{Optimization of the Sample Treatment}

Milk and milk products contain proteins that may be absorbed by the silanol groups of the positively charged capillary wall when an acidified BGE is adopted. In this work, casein was removed by isoelectric precipitation and filtration. Sample dilution before acidification allowed a homogeneous precipitation of caseins to be obtained (avoiding the formation of clumps). Both acetic and oxalic acids were tested to precipitate milk proteins at 2 different $\mathrm{pH}$ values; that is, the isoelectric $\mathrm{pH}$ of casein (4.60) and the selected $\mathrm{pH}$ of the BGE (3.75). Alkali ions were not affected in terms of $t_{m}$, and $R_{\mathrm{s}}$ was only slightly modified, whereas the alkalineearth elements showed a pronounced difference in $t_{m}$. In particular, an increase (approximately $1 \mathrm{~min}$ ) in the $\mathrm{t}_{\mathrm{m}}$ of $\mathrm{Mg}$ was measured when acetic acid was adopted. The concentration of $\mathrm{Na}$ did not vary significantly when the 2 acids were used for casein precipitation.

Finally, oxalic acid was adopted as a precipitating agent at the isoelectric $\mathrm{pH}$ of casein. As described previously, the sample preparation of milk products was simple and fast, and the whole determination procedure was achieved in approximately $15 \mathrm{~min}$. A sample of SMP analyzed by CZE as both a powder and 
Table 2. Effect of voltage on separation of $\mathrm{Na}$ and Li (internal standard) by capillary zone electrophoresis in pasteurized milk with a background electrolyte consisting of $10 \mathrm{mM}$ imidazole at $\mathrm{pH} 3.75$

\begin{tabular}{|c|c|c|c|c|}
\hline \multirow[b]{2}{*}{ Item } & \multicolumn{4}{|c|}{ Separation voltage $(\mathrm{kV})$} \\
\hline & 10 & 15 & 20 & 25 \\
\hline \multicolumn{5}{|l|}{ Migration time (min) } \\
\hline $\mathrm{Na}$ & 8.9 & 6.0 & 4.6 & 3.7 \\
\hline $\mathrm{Li}$ & 10.6 & 7.1 & 5.4 & 4.4 \\
\hline Baseline noise $(\mu \mathrm{V})$ & 36 & 41 & 34 & 38 \\
\hline Current $(\mu \mathrm{A})$ & 4.7 & 5.0 & 6.3 & 7.8 \\
\hline Na-Li resolution & 8.8 & 8.1 & 7.7 & 7.2 \\
\hline Normalized peak area ratio $\mathrm{Na}: \mathrm{Li}^{1}$ & 0.630 & 0.646 & 0.646 & 0.648 \\
\hline
\end{tabular}

${ }^{1}$ Peak area/migration time of $\mathrm{Na}$ divided by peak area/migration time of $\mathrm{Li}$.

a reconstituted sample showed $\mathrm{Na}$ contents that were not different $(P>0.05)$, proving that the extraction procedure was not affected by the initial water content of the sample. Because Na present in milk as a free ion, an equilibration step after SMP reconstitution is not required.

\section{CZE Method Validation}

Linearity. Quantification of Na was performed by a standard calibration method. The regression equation for the calibration curve was $\mathrm{y}=0.7168 \mathrm{x}+0.0058$, where $\mathrm{y}$ is the difference between the normalized peak area ratio $\mathrm{Na}: \mathrm{Li}$ of the sample and that of the blank solution, and $\mathrm{x}$ is the concentration of $\mathrm{Na}(\mathrm{mg} / 100 \mathrm{~mL})$ in the test solution. No peak distortion due to overloading was observed in the analyzed standard solutions, and the coefficient of determination calculated from the weighted linear regression analysis was 0.99 .

Sensitivity. Although the determination of $\mathrm{Na}$ in milk cannot be considered a trace analysis, an indication of the level at which detection becomes problematic has been provided for validation purposes. Using the adopted conditions, the limit of detection $(\mathrm{mg} / 100$ $\mathrm{mL}$ ), calculated as $3.3 \times \mathrm{SD}$ of a standard solution that contained $0.059 \mathrm{mg} \mathrm{Na} / 100 \mathrm{~mL}$, was equal to 0.24 $\mathrm{mg} / 100 \mathrm{~mL}$. The LOQ (i.e., the lowest concentration of analyte that can be determined with an acceptable level of repeatability, precision, and trueness; Eurachem Guide, 1998), which was calculated as $10 \times \mathrm{SD}$, was equal to $0.72 \mathrm{mg} / 100 \mathrm{~mL}$. The sample preparation procedure for CZE analysis was chosen to exceed the estimated LOQ value in the real samples analyzed.

Precision Parameters. The within-laboratory precision of the method was calculated and expressed in terms of intra- and inter-day repeatability. In cases of a single-laboratory study, in which different analysts and possibly different instruments and times are utilized, precision is characterized as intermediate precision or within-laboratory reproducibility (Horwitz and Albert,
2006). Different milk types were considered to evaluate the effect of both milk heat treatment and fat content (Table 3). The $\mathrm{RSD}_{\mathrm{r}}$ varied between 1.3 and $1.6 \%$, and the $\mathrm{RSD}_{\mathrm{R}}$ ranged from 1.9 to $2.4 \%$. Such data are lower than $\mathrm{RSD}_{\mathrm{r}}$ figures obtained in the international study for the determination of $\mathrm{Na}$ in milk products by FAAS (ISO/IDF, 2007) and by inductively coupled plasma optical emission spectrometry (Nöel et al., 2008). The HorRat value is a simple performance parameter that reflects the acceptability of a chemical method of analysis with respect to precision (Lin et al., 1993). The extrapolations of HorRat values to a single-laboratory validation study are expected to be from 0.3 to 1.5 (Poitevin et al., 2009). For the 4 milk samples analyzed, the HorRat values were all between 0.3 and 0.4. The levels of $r_{\text {rel }}$ and $R_{\text {rel }}$, which represent useful parameters for determining the expected variability between results when a sample is analyzed in duplicate, were always less than 4.4 and $6.7 \%$, respectively.

Recovery. Because $\mathrm{Na}$ is present in milk almost exclusively as free ions, the entire amount of this analyte can be measured from the isoelectric whey. To verify the efficiency of recovery and to detect a possible failure in the extraction procedure, test portions of milk and milk products were spiked with known amounts of Na. Spiking was done at 2 levels that corresponded to about 50 and $100 \%$ of the mean concentration of the sample (Table 4). In all cases, the recovery was in the range of 95.6 to $101.2 \%$, and no difference $(P>0.05)$ was observed between the 2 spiking levels.

Trueness. The trueness (i.e., the expression of how close a result is to the true value) was assessed on 13 samples, including drinking milk and a variety of milk products (Table 5), by comparison against the reference FAAS method (ISO/IDF, 2007). The data obtained by CZE were in agreement with those by FAAS, and no systematic trend of results was observed. As expected, the Na content was lower $(P<0.05)$ in the full-fat pasteurized milk than in the skimmed samples. McCance and Widdowson (2002) reported average Na contents 
Table 3. Precision parameters of a within-laboratory study on 4 milk samples for the determination of $\mathrm{Na}$ in milk by capillary zone electrophoresis

\begin{tabular}{|c|c|c|c|c|}
\hline \multirow[b]{2}{*}{ Parameter $^{1}$} & \multicolumn{4}{|c|}{ Milk type } \\
\hline & Unprocessed & $\begin{array}{l}\text { Pasteurized } \\
\text { (skimmed) }\end{array}$ & $\begin{array}{c}\text { Microfiltered } \\
\text { pasteurized }\end{array}$ & $\begin{array}{c}\text { UHT } \\
\text { sterilized }\end{array}$ \\
\hline Na content $(\mathrm{mg} / 100 \mathrm{~g})$ & 39.6 & 42.3 & 43.7 & 40.3 \\
\hline $\mathrm{r}(\mathrm{mg} / 100 \mathrm{~g})$ & 1.6 & 1.7 & 1.5 & 1.8 \\
\hline $\operatorname{RSD}_{\mathrm{r}}(\%)$ & 1.5 & 1.5 & 1.3 & 1.6 \\
\hline $\mathrm{r}_{\mathrm{rel}}(\%)$ & 4.1 & 4.2 & 3.5 & 4.4 \\
\hline $\mathrm{R}(\mathrm{mg} / 100 \mathrm{~g})$ & 2.1 & 2.3 & 2.4 & 2.6 \\
\hline $\operatorname{RSD}_{\mathrm{R}}(\%)$ & 1.9 & 2.0 & 2.0 & 2.4 \\
\hline $\mathrm{R}_{\mathrm{rel}}(\%)$ & 5.3 & 5.7 & 5.6 & 6.7 \\
\hline Predicted $\mathrm{RSD}_{\mathrm{R}}(\%)$ & 6.5 & 6.5 & 6.4 & 6.5 \\
\hline HorRat $_{R}$ & 0.3 & 0.3 & 0.3 & 0.4 \\
\hline
\end{tabular}

${ }^{{ }^{r}} \mathrm{r}=$ repeatability $; \mathrm{RSD}_{\mathrm{r}}=$ relative standard deviation of repeatability; $\mathrm{r}_{\mathrm{rel}}=$ relative repeatability; $\mathrm{R}=$ withinlaboratory reproducibility; $\mathrm{RSD}_{\mathrm{R}}=$ relative standard deviation of within-laboratory reproducibility; $\mathrm{R}_{\mathrm{rel}}=$ relative within-laboratory reproducibility; HorRat $_{R}=$ Horwitz ratio $\left(\mathrm{RSD}_{\mathrm{R}} /\right.$ predicted $\left.\mathrm{RSD}_{\mathrm{R}}\right)$.

of $43 \mathrm{mg} / 100 \mathrm{~g}$ for both full-fat and semiskimmed pasteurized milk and $44 \mathrm{mg} / 100 \mathrm{~g}$ for the skim milk.

Only the follow-on infant formula sample showed a mean value by CZE that was significantly different $(P<0.05)$ from that obtained by FAAS. In this case, we hypothesized that some Na present in the formulation of this milk-based product could not be measured by the extraction procedure adopted for CZE analyses. The lowest $\mathrm{Na}$ concentration was recorded for a sample of growth infant formula $(20 \mathrm{mg} / 100 \mathrm{~g})$ and the highest was for a processed cheese $(1,218 \mathrm{mg} / 100$ $\mathrm{g})$. Both of these levels, although they differed by a factor of 60 , were accurately measured by the proposed method. Furthermore, for all products, the analytical data were in accordance with the $\mathrm{Na}$ content declared on the label, where available, with the exception of the fermented milk sample.

Milk products represent a commodity group contributing to $\mathrm{Na}$ intake and, in some cases, declarations do not reflect the real $\mathrm{Na}$ content (Agarwal et al., 2011). To increase consumer awareness of the role of $\mathrm{Na}$ for a healthy lifestyle, it is important that the $\mathrm{Na}$ content be declared on the label and that the declared value should be accurate.

The samples of milk products analyzed in this work differed in their technological processes of manufacturing, including heat treatment, microfiltration, lactic fermentation, coagulation, and drying steps. Despite this, the proposed method gave accurate results with respect to the reference method.

\section{CONCLUSIONS}

This paper reports a rapid and reliable CZE method for the routine determination of $\mathrm{Na}$ in milk, cheeses, and other milk products. The adopted conditions (BGE consisting of $10 \mathrm{~m} M$ imidazole adjusted to $\mathrm{pH} 3.75$ by the addition of oxalic acid) guarantee a baseline separation of Na within 5 min. This simple-to-perform procedure is achieved using instrumentation commonly available in food quality control laboratories and it requires reduced consumption of hazardous reagents compared with the official FAAS method. The good linearity and satisfactory performance in terms of recovery, trueness,

Table 4. Recovery of $\mathrm{Na}$ in milk and cheese by capillary zone electrophoresis ${ }^{1}$

\begin{tabular}{lccr}
\hline Sample & $\begin{array}{c}\text { Na content } \\
(\mathrm{mg} / 100 \mathrm{~g})\end{array}$ & $\begin{array}{c}\text { Spiked Na } \\
(\mathrm{mg} / 100 \mathrm{~g})\end{array}$ & $\begin{array}{c}\text { Recovery } \\
(\%)\end{array}$ \\
\hline Unprocessed milk & 42.3 & 20.2 & 98.4 \\
Pasteurized milk (semiskimmed) & 42.3 & 41.1 & 100.4 \\
& 41.7 & 20.1 & 98.3 \\
UHT-sterilized milk & 41.7 & 40.7 & 101.2 \\
Quark cheese & 42.8 & 19.7 & 95.6 \\
& 42.8 & 40.2 & 98.6 \\
& 243.3 & 118.2 & 99.2 \\
\hline
\end{tabular}

${ }^{1}$ The second row of data within each sample type refers to the second level of spiking, corresponding to about $100 \%$ of Na content. 
Table 5. Comparison of Na contents (mg/100 g) measured by capillary zone electrophoresis (CZE) and flame atomic absorption spectrometry (FAAS) with the value declared on the label in different milk and milk products

\begin{tabular}{llrl}
\hline Sample & $\begin{array}{l}\text { Declared } \\
\text { on the label }\end{array}$ & CZE & \multicolumn{1}{c}{ FAAS } \\
\hline Milk & & & \\
Pasteurized (skimmed) & $0.05 \mathrm{~g} / 100 \mathrm{~mL}$ & $42.3 \pm 0.4^{\mathrm{a}}$ & $44.1 \pm 1.0^{\mathrm{a}}$ \\
Pasteurized (semiskimmed) & $0.05 \mathrm{~g} / 100 \mathrm{~mL}$ & $40.1 \pm 0.6^{\mathrm{a}}$ & $41.5 \pm 0.6^{\mathrm{a}}$ \\
Pasteurized (whole) & $0.05 \mathrm{~g} / 100 \mathrm{~mL}$ & $38.2 \pm 0.5^{\mathrm{a}}$ & $39.0 \pm 0.4^{\mathrm{a}}$ \\
Microfiltered pasteurized & $0.05 \mathrm{~g} / 100 \mathrm{~mL}$ & $40.6 \pm 0.8^{\mathrm{a}}$ & $42.0 \pm 0.6^{\mathrm{a}}$ \\
$\quad$ UHT sterilized & $0.05 \mathrm{~g} / 100 \mathrm{~mL}$ & $40.8 \pm 0.9^{\mathrm{a}}$ & $40.1 \pm 1.2^{\mathrm{a}}$ \\
Milk products & $\mathrm{ND}$ & & \\
Skim milk powder & $0.06 \mathrm{~g} / 100 \mathrm{~mL}$ & $44.9 \pm 0.5^{\mathrm{a}}$ & $437.2 \pm 17.8^{\mathrm{a}}$ \\
Fermented milk & $20 \mathrm{mg} / 100 \mathrm{~mL}$ & $17.9 \pm 0.3^{\mathrm{a}}$ & $17.1 \pm 0.6^{\mathrm{a}}$ \\
Growth infant formula (liquid) & $34 \mathrm{mg} / 100 \mathrm{~mL}$ & $30.2 \pm 0.4^{\mathrm{a}}$ & $34.4 \pm 0.2^{\mathrm{b}}$ \\
Follow-on infant formula (liquid) & $\mathrm{ND}$ & $596.3 \pm 4.7^{\mathrm{a}}$ & $596.0 \pm 20.8^{\mathrm{a}}$ \\
PDO ${ }^{3}$ Pecorino Toscano & $\mathrm{ND}$ & $617.7 \pm 9.0^{\mathrm{a}}$ & $657.6 \pm 45.4^{\mathrm{a}}$ \\
Grated hard cheese & $250 \mathrm{mg} / 100 \mathrm{~g}$ & $243.3 \pm 11.4^{\mathrm{a}}$ & $264.3 \pm 10.7^{\mathrm{a}}$ \\
Quark cheese & $1.2 \mathrm{~g} / 100 \mathrm{~g}$ & $1,218.3 \pm 15.5^{\mathrm{a}}$ & $1,179.3 \pm 25.5^{\mathrm{a}}$ \\
Processed cheese & &
\end{tabular}

${ }_{\mathrm{a}, \mathrm{b}}$ Mean values within a row with different superscript letters are different $(P<0.05)$.

${ }^{1}$ Mean values \pm standard deviations of 3 determinations.

${ }^{2}$ Not declared.

${ }^{3}$ Protected Denomination of Origin.

and precision favor the adoption of this method for routine monitoring of Na content. The development of new products with reduced $\mathrm{Na}$ content is not an easy task, and further studies are needed to address the quality and stability of the finished food. Furthermore, the effective implementation of changes in the manufacturing processes will need repeated controls of $\mathrm{Na}$ content at each step of the production chain; hence, the dairy industry would benefit significantly from the availability of a rapid analytical method.

\section{REFERENCES}

Agarwal, S., D. McCoy, W. Graves, P. D. Gerard, and S. Clark. 2011. Sodium content in retail Cheddar, Mozzarella, and process cheeses varies considerably in the United States. J. Dairy Sci. 94:16051615.

AOAC. 2007. Official Methods of Analysis 18th ed. Association of Official Analytical Chemists, Gaithersburg, MD.

Cruz, A. G., J. A. F. Faria, M. A. R. Pollonio, H. M. A. Bolini, R. M. S. Celeghini, D. Granato, and N. P. Shah. 2011. Cheeses with reduced sodium content: Effects on functionality, public health benefits and sensory properties. Trends Food Sci. Technol. 22:276-291.

Ehling, S., S. Tefera, R. Earl, and S. Cole. 2010. Comparison of analytical methods to determine sodium content of low-sodium foods. J. AOAC Int. 93:628-637.

Eurachem Guide. 1998. The Fitness for Purpose of Analytical Methods: A Laboratory Guide to Method Validation and Related Topics. Accessed Nov. 9, 2011. http://www.eurachem.org/guides/pdf/ valid.pdf.

François, C., P. Morin, and M. Dreux. 1995. Separation of transition metal cations by capillary electrophoresis. Optimization of complexing agent concentrations (lactic acid and 18-crown-6). J. Chromatogr. A 717:393-408.

Gaucheron, F. 2011. Milk salts. Pages 908-940 in Encyclopedia of Dairy Sciences. Vol. 3. J. W. Fuquay, P. F. Fox, and P. L. H. McSweeney, ed. Elsevier Academic Press, London, UK.
Guinee, T. P., and P. F. Fox. 2004. Salt in cheese: Physical, chemical and biological aspects. Pages 207-259 in Cheese Chemistry, Physics and Microbiology. Vol. 1. P. F. Fox, P. L. H. McSweeney, T. M. Cougan, and T. P. Guinee, ed. Elsevier Academic Press, Amsterdam, the Netherlands.

Horwitz, W., and R. Albert. 2006. The Horwitz ratio (HorRat): A useful index of method performance with respect to precision. J. AOAC Int. 89:1095-1109.

IDF (International Dairy Federation). 1991. Milk and milk products. Precision characteristics of analytical methods - Outline of collaborative study procedure. IDF Standard No 135B. International Dairy Federation, Brussels, Belgium.

ISO/IDF. 2007. Milk and milk products-Determination of calcium, sodium, potassium and magnesium contents-Atomic absorption spectrometric method. Standard ISO8070:IDF119. International Dairy Federation, Brussels, B. International Standard Organization, Geneva, Switzerland.

ISO/IDF. 2010. Milk and milk products-Determination of calcium, copper, iron, magnesium, manganese, phosphorus, potassium, sodium and zinc contents - Inductively coupled plasma atomic emission spectrometric method (ICP-AES). Standard ISO/CD 15151:IDF229. International Dairy Federation, Brussels, B. International Standard Organization, Geneva, Switzerland.

Izco, J. M., M. Tormo, A. Harris, and P. S. Tong. 2003. Optimization and validation of a rapid method to determine citrate and inorganic phosphate in milk by capillary electrophoresis. J. Dairy Sci. 86:86-95.

Jenness, R., N. P. Wong, E. H. Marth, and M. Keeney. 1999. Fundamentals of Dairy Chemistry. Aspen Publisher, Gaithersburg, MD.

Kaplan, N. M. 2000. The dietary guideline for sodium: Should we shake it up? Am. J. Clin. Nutr. 71:1020-1026.

Lin, T. I., Y. H. Lee, and Y. C. Chen. 1993. Capillary electrophoretic analysis of inorganic cations. Role of complexing agent and buffer pH. J. Chromatogr. A 654:167-176.

Macka, M., and P. R. Haddad. 1997. Determination of metal ions by capillary electrophoresis. Electrophoresis 18:2482-2501.

Mato, I., S. Suárez-Luque, and J. F. Huidobro. 2005. A review of the analytical methods to determine organic acids in grape juices and wines. Food Res. Int. 38:1175-1188.

McCance, R. A., and E. M. Widdowson. 2002. The Composition of Foods. 6th ed. Royal Society of Chemistry, Cambridge, UK. 
Morin, P., C. François, and M. Dreux. 1995. Capillary electrophoresis of alkali and alkaline-earth cations with imidazole or benzylamine buffers. J. Liq. Chromatogr. 17:3869-3888.

Nöel, L., M. Carl, C. Vastel, and T. Guérin. 2008. Determination of sodium, potassium, calcium and magnesium content in milk products by flame atomic absorption spectrometry (FAAS): A joint ISO/IDF collaborative study. Int. Dairy J. 18:899-904.

Pacáková, V., P. Coufal, and K. Štulík. 1999. Capillary electrophoresis of inorganic cations. J. Chromatogr. A 834:257-275.

Poitevin, E., M. Nicolas, L. Graveleau, J. Richoz, D. Andrey, and F. Monard. 2009. Improvement of AOAC official method 984.27 for the determination of nine nutritional elements in food products by inductively coupled plasma-atomic emission spectroscopy after microwave digestion: Single laboratory validation and ring trial. J. AOAC Int. 92:1484-1518.

Pretswell, E. L., A. Brian, B. McGaw, and A. R. Morrisson. 1995. The comparison of capillary zone electrophoresis and atomic spectroscopy for the determination of the cation content of a standard reference material IAEA-A-11 milk powder. Talanta 42:283-289.
Sádecká, J., and J. Polonský. 1999. Determination of inorganic ions in food and beverages by capillary electrophoresis. J. Chromatogr. A $834: 401-417$.

Soyeurt, H., D. Bruwier, J. M. Romnee, N. Gengler, C. Bertozzi, D. Veselko, and P. Dardenne. 2009. Potential estimation of major mineral contents in cow milk using mid-infrared spectrometry. J. Dairy Sci. 92:2444-2454.

Suárez-Luque, S., I. Mato, J. F. Huidobro, and J. Simal-Lozano. 2007. Determination of major metal cations in milk by capillary zone electrophoresis. Int. Dairy J. 17:896-901.

Sze, K. L., W. S. B. Yeung, and Y. S. Fung. 2007. Separation and determination of metal cations in milk and dairy products by $\mathrm{CE}$. Electrophoresis 28:4156-4163.

Valsecchi, S. M., and S. Polesello. 1999. Analysis of inorganic species in environmental samples by capillary electrophoresis. J. Chromatogr. A 834:363-385.

WHO. 2010. Creating an enabling environment for population-based salt reduction strategies. Accessed Nov. 9, 2011. http://www.who. int/dietphysicalactivity/reducingsalt/en. 